Michael Cawood Green and Tony Williams

\author{
On reflection: The role, mode and medium of the reflective component in \\ practice as research
}

\begin{abstract}
A key criterion in the recognition of practice as research is the inclusion of some form of critical self-reflection as a component of the creative project. This requirement that some form of complementary/supplementary discourse is necessary to establish the research status of creative practice is currently the subject of scrutiny and contestation across a number of disciplines. Noting how much work has been done in this area within the doctoral degree in Creative Writing in Australia, this paper explores some of the problematic areas in the formal recognition of practice as research within the UK's research structures and processes. It argues that the scholarly rubric expected of the reflective component is not always the most appropriate medium through which creative work may be recognised as research.

It considers tensions implicit in the dual role of supplementary discourses: that of documenting practice for institutional purposes and that of articulating and generating new knowledge about practice. The disciplinary placing of Creative Writing in the UK context also complicates its relation to other forms of practice as research. This paper argues that the recognition of a wider range of modes and media for supplementary discourses would allow the generation of new and different knowledge about creative practice, and make that knowledge differently available to researchers.
\end{abstract}

Keywords: Reflection, practice, research

\title{
The institutional context in the UK
}

It was encouraging to hear Bruce Brown, Professor of Design and Pro-Vice-Chancellor for Research at the University of Brighton as well as Chair of Main Panel D (Arts and Humanities) in the UK's Research Excellence Framework 2014 [1], declare at a symposium on 'The Future of Practice Research' held at Goldsmiths, University of London in June 2015 [2], that the argument for practice research [3] has been won. His forthright conclusion - 'Get over it and get on with it' - came however after an address in which he spent much of his time speaking to a necessary 'evidence base for non-textual research outputs' [4].

This requirement for 'additional information' accompanying practice outputs, he said, drawing on 'nearly thirty years of involvement in the assessment and public funding of research in the arts and humanities,' had been an evolving issue in the history of the UK's research evaluation exercises. The submission of practice-based outputs was first allowed after changes in the Research Assessment Exercise (which was replaced by the REF [5]) in the mid-1990s, at that time accompanied by only a title plus a few words about the work. In the 2001 RAE exercise a request for a descriptive statement, 'where necessary,' was introduced, and in RAE2008 and REF2014, the possibility of submitting an additional research portfolio. Both statement and portfolio have never been a requirement, but an option where the practice works did not 'display or make available the research imperatives of themselves' (Brown 2015).

If providing an adequate evidence base is the ground on which the battle for practice as research has been won, this has not been an easy, even, or conclusive victory across institutions, disciplines, and research funders in the UK, let alone a broader international context. In its simplest form, as some sort of statement provided by the practitioner setting out 'the research imperatives and research process' and giving any 'descriptive and contextualising information' that would make this more evident, such accompanying material can be seen as a relatively neutral supplement to the researcher's practice. But in practice, 'in practice,' that is, this is not always the case (Brown 2015). 


\section{Michael Cawood Green \& Tony Williams TEXT Vol 22 No 1}

For a start, attempts to encourage the submission of practice research in REF2014 had little effect: only 36 per cent of all the research submitted in the humanities was practice-led [6], much the same as in the RAE in 2008. In Browne's view, given the detailed statement released to support the submission of practice research (setting out formally the views he was sharing at the Goldsmiths' event) [7], 'these proportions should have been reversed'. This suggested that either the volume of practice-based work produced remained low, or the outcomes were below REF standards, or - and Brown admitted that this was the more likely explanation - there was 'some mistrust about how this work was handled by the panels' and a general 'suspicion of the assessment processes' [8].

There were problems too, amongst those practitioners who did submit their work to the REF. While, in Brown's view, the research assessment panel 'bent over backwards to accommodate the assessment of practice base research,' in some cases it was still, without some sort of a statement accompanying the practice, 'very, very difficult to see what the research imperatives were that underpinned [the] research output' [9].

In REF sub-panels 34 (Art and Design: History, Practice and Theory) and 35 (Music, Drama, Dance and Performing Arts) [10] 'the percentage I think of unclassified work [11] is quite high at 3 per cent,' Brown reported, adding 'I would say the majority of that was not because the work was poor, it is because it was very difficult to tell whether it was research or not, or whether it was just practice.' 'For me,' he said, 'there is a big issue here that's quite urgent: ... in REF2020 [now scheduled for 2021] you should not make research portfolios an option, they must be a requirement for everything that's non-text...' [12].

Brown's feeling that the REF administrators have been 'too liberal' in this regard suggests a future eroding of optionality when it comes to the submission of research statements and portfolios. Brown also spoke to a tightening up of what would be expected of the accompanying research statements provided by practitioners: many in REF2014 were, in his words, 'a mess' - not much more than 'personal CVs and descriptive accounts of someone's career' that did little to help those serving on REF sub-panels to tell if the practices they were assessing were indeed 'research'. 'People were not,' said Brown, 'exercising discrimination judgement over the research report they chose to submit' [13].

What the REF panels were looking for, he said, was 'not another piece of research or a post hoc description of the research but ... an additional parallel piece of work that anybody who was not engaged in the work could look at and could see what the research questions were, the dissemination processes all the good practices of academic research that were underpinning this work.' Good examples of the research report, he said, 'weren't reiterations of the fundamental basic research; they were documents in themselves that explained more than the research itself was able to explain'.

We catch here an echo of Brown's disciplinary base in Design. The 'assumption that competent practitioners usually know more than they can say' is a central tenet in Donald Schön's The Reflective Practitioner: How professionals think in action (1983: 8), a seminal text in design theory. Drawing on John Dewey's How we think: a restatement of the relation of reflective thinking to the educative process (Dewey 1998 [1910; revised 1933]), the work that introduced the concept of 'reflective conversation with the situation' (Schön 1983: 163) as a way of looking at an epistemology of practice that is based on examining what practitioners do, Schön defines reflective practice as the practice by which professionals become aware of their implicit knowledge base and learn from their experience. His ideas on 'reflective activity,' which includes 'reflective practice', 'reflection-in-action', and 'knowing-in-action,' have been taken up in a wide range of practice-based disciplinary areas, from nursing to teacher-training, psychotherapy, city planning, engineering, management, law, and creative practice in various forms, allowing us to widen this discussion beyond simply the REF.

Reflection in Schön's sense has found its way, with or without reference to its initial sources, into the assumptions underpinning the definition of practice research, and has become the primary means by which creative work is defined within the UK academy as research. This is the case when it comes to bidding for research funding, successful grant capture, reporting back to the research councils on completed projects, presenting one's creative work as research to one's institution, and publishing creative work in some scholarly journals, where the inclusion of some form of critical self-reflection is a key criterion in the recognition of creative practice as an original contribution to knowledge. The UK's Arts and Humanities Research Council for example, accepts that: 'Creative output can be produced, or practice undertaken, as an integral part of a research process,' but it 'expects ... this practice to be accompanied by some form of documentation of the research process, as well as some form of textual analysis or explanation to 
support its position and as a record of ... critical reflection'. It accepts too that: 'Equally, creativity or practice may involve no such process at all,' but in this case 'it would be ineligible for funding' [14].

The inclusion of some form of critical self-reflection in the form of an accompanying or parallel piece of work as a necessary adjunct to the creative project is most clearly formalised in the requirement for an exegetical or critical component in the Creative Writing doctoral degree; although the creative component does, typically, carry the heaviest weighting, it is the additional reflective commentary - a scholarly-informed reflection on the creative process, weighted at anything from 20-50 per cent of the overall degree project - that does the work of transforming or translating the creative work into a credit-bearing academic research exercise.

This requirement is increasingly the subject of scrutiny and contestation, with the question of 'what kinds of theoretical discourses can and should be used in creative writing exegeses' (Bourke \& Neilsen 2004) haunting the idea that a complementary/supplementary discourse is essential for recognising the creative as a mode of research. In Australia, principally, a vigorous debate has been underway for some time concerning the 'Evolution of the exegesis' and the increasing 'radicalisation of the Creative Writing doctorate' (Krauth 2011; see also Perry 1998; Milech \& Schilo 2004; Hetherington 2010; McNamara 2012; Watkins \& Krauth 2016; Brien \& McAllister 2016). This has only recently, and for the most part in specific disciplinary areas (see music below), begun to come to the fore in common working definitions of practice as research across the academy. A similar effort is needed in university structures and research councils to increase the recognition of practice as research and challenge definitions of practice as research that reduce it to an easy set of passive descriptors or non-negotiable formulations of what is considered systematic, rigorous, and communicable.

Rachel Hann, lecturer in scenography at the University of Surrey and director of postgraduate research for the Guildford School of Acting, points out that one of the very real costs of winning the right to conduct research through practice from academic administrators (what she calls the 'first wave' of Practice Research) has been the risk of creating 'a culture where Practice Research is conducted for the purpose of administration: for evidencing an individual's research profile to be assessed, holistically, by exercises such as the REF,' resulting in 'the full portfolio of evidence [being] directed towards the needs of the REF panel rather than the discipline at large' (Hann 2015). She, and other practice researchers such as Tess Brady, are concerned that the required exegesis functions mainly as a 'ticket to satisfy the gatekeepers admitting entrance to the academy's conservative research club' (Brady 2000). Hann therefore feels that a 'second wave' is now necessary, one in which the primary aim for the documentation accompanying a practice research output is to 'share our findings more openly' and 'evidence to our broader communities the innate value of practically borne knowledge.' This, she says, will ensure that 'the new insights acquired through our collective processes of craft, action and dialogue are sustained beyond any one individual or event' (Hann 2015).

While Hann insists that 'Practice Research is not an administrative task,' John Croft, composer and lecturer in music at Brunel University, presents an even more radical challenge captured in the declarative title of his paper, 'Composition is not research' [15]. The opening lines of this short, pungent, and much-discussed publication have taken on something of an iconic status for a number of practitioners in many mediums working in the university context. 'There are,' writes Croft, 'by and large, two kinds of composers in academia today - those who labour under the delusion that they are doing a kind of "research", and those who recognise the absurdity of this idea, but who continue to supervise $\mathrm{PhD}$ students, make funding applications, and document their activities as if it were true.' 'Composing,' he says 'might on occasion depend on research' but research is never 'actually the composition of music'. As for reflecting on the creative process involved: 'after all the explications of technique, the compositionally important thing would remain unexplained and untouched' (Croft 2015: 6).

In an extended and sometimes fierce debate with Croft, Ian Pace, pianist and lecturer in music at City University London, asserts in an equally bluntly entitled paper, that 'Composition and Performance can be, and often have been, Research' (2016). Pace accepts Croft's 'basic formulation that composition is not intrinsically research,' but he insists that, like performance, it is an output, 'which can entail a good deal of research' (Pace 2016: 66).

For Pace, then, 'composition-as-research, and performance-as-research (and performance-based research) are real activities; the terms themselves are just new ways to describe what has gone on earlier, with the addition of a demand for explicit articulation to facilitate integration into academic structures' (2016: 70). 'What is being asked, not unfairly,' says Pace, 'of a composer employed in a research-intensive university is that at the least they verbally articulate the 


\section{Michael Cawood Green \& Tony Williams TEXT Vol 22 No 1}

questions, issues, aims and objectives, and stages of compositional activity, to open a window onto the process and offer the potential of use to others' (67). 'Documentation,' he concludes, 'does not make something research, just helps a little with making research more accessible’ (Pace 2015).

There is, however, another harder, more militant position within musicology. Whereas for Pace, 'documenting process can surely do no harm' (2015), Camden Reeves, composer and head of Music at the University of Manchester, is adamant that it does. Arguing that 'research is intrinsic to compositional outputs' and that therefore it 'does not require logo-centric explication for it to be apparent,' Reeves states that 'The music itself must provide evidence (QED) as to its viability in application, i.e. its musical potential. N.B.', he writes (Reeves 2015: 1), clearly with Brown's position above in mind, 'Some of the feedback for REF2014 worryingly implies that evidence should rest in accompanying statements and/or portfolios, rather than in the music itself' (2).

Reeves believes that 'the requirement of 300-word statements is in many cases not simply unnecessary; making this a requirement is actually detrimental to the future progress of compositional research' (2). His reasoning is that

Some composers can think that way, as they are dealing with a research agenda for which a written mode of discourse with which to discuss it already exists. But for others this is not the case. And some composers just don't think that way. They think about music in terms of music, and respond to music through music. (3)

Implicit in this distinction that includes but goes beyond who has access to specific forms of discourse or what may be expressed in them [16] is a more general aspect of the creative/reflexive relationship that has not been sufficiently considered (despite figuring largely in discussions about the supplementary exegesis in the $\mathrm{PhD}$, mainly in Australia) in debates and definitions to do with the research status of practice: the matter of voice.

In reflecting on his or her work in some sort of accompanying statement or portfolio, a practitioner must adopt at least two distinct voices: that of a creative practitioner working to varying degrees intuitively in or against the conventions of a particular creative mode, and that of a scholarlyinformed commentator reflecting through the academic conventions defining research - the presence of a research question informing the project, what is significant and original about the creative work, how it relates to an appropriate literature review, etc. Even in the case of practitioners who want and are able to 'articulate their research through written texts,' (Reeves 2015: 3) the assumption that the academic mode gives some sort of transparent or unmediated access to whatever it is in the creative work that makes it an original contribution to knowledge is problematic.

The problem is demonstrated clearly in a passage from Diary of a Bad Year by JM Coetzee, an extraordinarily self-reflexive text even within the canon of so extraordinarily self-reflexive a writer:

At the end of a day of writing-work I emerge with pages of what I am accustomed to call what I wanted to say. But in a more cautious spirit I now ask myself: Are these words, printed out on paper, truly what I wanted to say? Is it ever good enough, as a phenomenological account, to say that somewhere deep inside I knew what I wanted to say, after which I searched out the appropriate verbal tokens and moved them around until I had succeeded in saying what I wanted to say? Would it not be more accurate to say that I fiddle with a sentence until the words on the page "sound" or "are" right, and then stop fiddling and say to myself, "That must be what you wanted to say"? If so, who is it who judges what sounds or does not sound right? Is it necessarily I ("I")? (Coetzee 2007: 196)

'If so, who is it who judges?' The lived writerly experience of that crucial reflective question captures something of what Paul Williams, himself a practice-led researcher, notes of 'the issue of authorship and the authority of a so-called "author" of an exegesis':

An author is not quite the same person as the one who writes about being an author. The student writing an exegesis constructs an authorial persona, or as Krauth suggests, wears the disguise of an author to write her creative work. But to comment on her own work, she may feel fraudulent, as if she is second guessing the real intent of the author, or the meaning and worth of the artefact intended. This person, the exegete, is interpreting, in the same position as the critic, or scriptor: words, culture, language pass through her. She cannot claim 
to be the author of the work and to have firsthand knowledge of its meaning, only an observation of its construction. An exegesis then, if it is to be an honest response to the artefact, must acknowledge the tentative nature of its author, of its writing, of its truth. (Williams 2016)

Williams, lecturer in Creative Writing at the University of the Sunshine Coast, gives an indication here of the kinds of reflection on reflection underway in doctoral degrees in Australia; such crucial considerations as to the multiple personae, even identities, brought in to play in creative/reflexive praxis do not as yet appear anywhere in considerations of how practice may be identified as research in the broader administrative processes of the academy when it comes to the submission of practice as research. It seems that writers in the academy are assumed to be familiar with the terms upon which their outputs will be recognised as research, know the terms upon which this is done, and will apply these to their practice, giving it the 'transparency and accessibility' Brown calls for in REF practice research submissions.

The issue of locating the identity of the persona engaged in the twinned but not identical activities of 'practice' and 'research' (in the primarily reflective sense expected of the scholarly commentary) is problematised further by poet/short story writer and professor of Creative Writing at Lancaster University Graham Mort's identification of other areas of the 'unease that surrounds creative writing and notions of research in the academy' (Mort 2013: 21). If Mort were to fill out a REF return in relation to a story, he writes in 'Leverets,' a 'combination of an original short story and an essay exploring its genesis, antecedents and composition' (2013: 5),

I would have to comment upon its research strategies, impact and significance - and yes, I can cite contributory experience, fieldwork and texts along with its key thematic elements. I can point to the peer-reviewed status of this publication as a form of validation. But these circumstances also seem evasive, to sidestep the story itself which is essentially affective ... we cannot consider its textual and narrative manifestations without stumbling into the subjectivities that initiate, shape and activate it in the reader's mind. (Mort 2013: 21)

If Williams confirms Coetzee's sense of the split identities emerging in the move from first to second person in the passage from Diary of a Bad Year ("That must be what you wanted to say"?'/"who judges what sounds or does not sound right? Is it necessarily I ("I")?' (Coetzee 2007: 196), Mort adds the issue of the wider location of meaning in what he calls 'the imaginatively affective process' (Mort 2013: 15). The short story may well be 'a textual artefact with literary form,'

but it is also a locus of shared consciousness, abandoned by the writer, rescued, decoded and activated in a new experimental sense by the reader. The story anticipates or implies a reader who does not exist... (2013:21)

How to take into account the generative relationship between writer and reader is another of the many difficulties that a creative artefact presents for academic research paradigms; the creation of meaning is not located 'within' the writer, there to be reflected upon, but is produced externally, in the act of being read by others, varying therefore potentially infinitely. As Mort puts it, 'the irritant for many writers working within academia is the sense that definitions of research lack this essential open-endedness, that the story itself is incomplete without accompanying exegesis' (2013: 22).

We are back here at Brown's telling phrase: a good research statement/portfolio is there to explain 'more than the research itself was able to explain'. The shift in agency here from Schön's formulation ('competent practitioners usually know more than they can say' [1983: 8]) is interesting, suggesting that the failure of the work to make its 'research content ... self-evident' (REF2014 2012: 87) forces the writer into the position of speaking for it, at least in this respect. We are close here to one of the real, felt on the bone reasons for the 'mistrust' and 'suspicion of the assessment processes' that Brown is at a loss to explain above. Coupled with the feeling of being in some way 'fraudulent' ('as if she is second guessing the real intent of the author') that Paul Williams refers to above, this produces the heart-felt 'Mea culpa' (Mort 2013: 22) with which Mort concludes his publication of his story 'Leverets' in the form of a journal article that includes the kind of 'additional information' a process like the REF might require - even when, in this case, the 'additional information' provided is presented as a challenge to the very need for that 'additional information.'

Along with the fact that many academic institutions do not recognise single short stories as REF 'outputs' (even if in length, complexity, and significance some may compare well with a scholarly 


\section{Michael Cawood Green \& Tony Williams TEXT Vol 22 No 1}

essay), it is a risky research strategy to submit a short story, indeed many if not most creative works, 'without additional material,' trusting that 'the output' is 'in itself deemed to constitute sufficient evidence of the research.' For if one has not spoken up for one's work in an accompanying reflection, one must depend on that second, commenting voice, silent though it is, still being heard, ghosting through the creative work and making itself felt [17].

As we have seen, Brown is reluctant for practitioners to rely on this kind of implicit, internalised statement for their research status - and dissemination - in REFs to come, recommending that a research statement and/or portfolio be required of all 'non-textual,' practice outputs. As things stand too, any current funding bid to a research council or charity requires the kind of scholarly rubric and academic positioning caricatured by Croft (whether written by practitioners who "labour under the delusion that they are doing a kind of "research"" or "those who recognise the absurdity of this idea' [Croft 2015: 6]), as will any project for a $\mathrm{PhD}$ in a practice-based discipline, or an application for a scholarly/writerly academic post, or a research report required by one's institution, even the kind of public profile one has to present for front-of-house university purposes. The creative industries too, demand various versions of convention-driven modes of reflecting and commenting on one's own work, be this a writer's pitch to an agent or publisher, marketing exercises, programme notes, exhibition guides, launch addresses, media appearances, interviews and so on - and on.

In all these cases and more, a practitioner will to a greater or lesser extent have to ignore, avoid, or supress many of the myriad, subtle, often inexpressible dimensions of reflection, go through the contortions of sifting through the infinite complexities of the writerly experience to adapt them for a particular expressive occasion. Where, though, we have an opportunity to shape the methods, modes and forms (and, indeed the institutional constraints) of our own research, we ought to look for ways to capture and articulate all aspects of reflection, particularly those which are typically elided by conventional approaches.

We are not then suggesting that the idea of reflecting on one's work for research purposes be rejected out of hand, being as it is one of the many ways in which creative work is presented, disseminated, and yes, assessed and rated; what we would like to call for is institutional acknowledgement that the scholarly rubric expected of reflection in the practice-as-research context is not in all cases the most relevant or appropriate medium through which creative work may be recognised and accredited as research. A broader range of discursive strategies, appropriate to the practice in hand - be this internal to the creative work or accompanying it in other forms and media - will allow practice not just to conform to research criteria, but contribute to opening those criteria up in ways that can accommodate some of the fundamental limitations felt by practice researchers.

\section{Alternative modes}

The wider discussion about discourses supplementary to practice as research of course relates mainly to non-textual research outputs. If those discourses are primarily conceived as providing what Bruce Brown called an 'evidence base for non-textual research outputs,' then it should not be a surprise if in their wider conception they do not quite fit with the interests of research in creative writing. The outputs of research in creative writing typically are textual, and in this sense do not need documenting or evidencing in the same way that, for example, an exhibition or performance may do. It is important to distinguish evidence of outputs from evidence of process. In creative writing, the outputs themselves stand as their own evidence in a way that non-textual practices may not be able to achieve; but presenting a novel does not in itself provide evidence of the research process that produced it. It is precisely evidence of process (in some form) which enables creative writing outputs to qualify as research in the REF and in other institutional contexts.

Providing that kind of evidence might be purely instrumental in purpose, especially given Brown's insistence, in relation to the REF2014 accompanying statement, that this should be "not another piece of research.' By supplying information about critical context, research questions and methodology, an accompanying statement should demonstrate that and how a practice-led output constitutes a research outcome; but it expressly should not itself generate knowledge.

Such a constraint makes sense in relation to a 300-word statement produced specifically to support a quality audit like the REF. But it is less adequate in relation to supplementary discourses in general. The role of supplementary discourses in 'articulating' research covers a lot of ground between this kind of instrumental evidencing on the one hand, and a reflective output on the other which does constitute 'another piece of research' in that it articulates (and even generates) 
knowledge which the associated practice outputs cannot in themselves make available to other researchers.

Institutional requirements for supplementary discourses, such as the REF and such as practice disciplines' ongoing (if declining) anxieties about being accepted by critical colleagues, risk deflecting practice researchers from the benefits of these more expansive forms of reflection. As Hann points out, producing reflective work for the 'purpose of administration' risks occluding the more meaningful purpose a practice researcher may have in talking about their research: that of articulating more clearly to themselves and others how they do what they do (Hann 2015). The distinction may be between documenting and archiving research outputs and processes on the one hand (where discourse is supplementary in the sense of supporting outputs without itself generating or constituting outputs), and, on the other, articulating and reflecting on practice in a text which is a research output in its own right (where discourse is supplementary in the sense that it can only exist if the practice exists). In essence the distinction is between an institutional chore which does not in itself advance practice either in itself or as research, and a generative element in the research process which, while being 'supplementary' to the production of an artefact or performance and in that sense 'not practice', nevertheless helps the researcher to advance their own practice and, by articulating it, to advance the practice of other researchers in the future. The challenge posed by Hann and others, and taken up in this paper, is to make supplementary discourses useful to the practices they are supplementary to.

As is often the case with distinctions, the reality may be messier, not least because documenting and articulating, for example, do not preclude each other, may be realised differently in different texts, and anyway may mean different things in different disciplinary contexts. This last point is important in relation to creative writing. In the UK and to a lesser degree across the Englishspeaking world, English Literature has been the parent discipline of Creative Writing (Gupta 2010: 90-98) and this historical contingency has shaped creative writers' conceptions of research processes and outputs. In particular, the supplementary discourse has been modelled on the humanities journal article. This has helped Creative Writing to realise the forms of rigour associated with that form: clarity of argument, properly referenced evidence, and convincing critical contextualisation are three obvious examples. It is not our purpose in this paper either to disparage the journal article as a mode or to undermine the ways in which it can, and does, provide a way for thinking in Creative Writing to achieve rigour.

However, it is also important to acknowledge that in developing and asserting new modes for critical reflection on practice, Creative Writing researchers are not bound to work only in relation to a larger discipline which is fixed and unchallenged in its values, processes and forms. For one thing, the modes and methods of the humanities have always been, and remain, subject to challenge and development (witness, for example, the rise of the digital humanities and more recently of 'experimental humanities' (Dimock 2017). For another, as Creative Writing gains in confidence as a research discipline it increasingly looks towards other practice-led disciplines, particularly in the arts. Its textual outputs provide a challenge to any engagement with non-textual practices, and the shared concern with literary texts means that the relationship with English Literature will always be a close one. But engaging with other practices opens possibilities for the supplementary discourse beyond the humanities journal article.

Above, we suggested that the assumption that the academic mode allows practice to be represented (evidenced, articulated) in a transparent or unmediated way is problematic. This is not simply a call for accessibility to laypeople. Robin Nelson asserts that 'the complementary writing of artists [should] afford access to the complex process of making to non-specialists' (Nelson 2013: 36-7). While that may be a laudable principle, our concern here is with the challenge of affording access not only to non-specialists but to specialists too. In UK Creative Writing, the scholarly article is the conventional medium of reflection, but it is not neutral. If the article elides, for example, the affective element in practice (what it is really like to write), then it may be presenting a distorted view of the process it purports to articulate.

Let us imagine a typical scenario in which a writer undertakes reflection as part of a writing research project. She reads deeply, reflects as she writes, and does all the things we might usually expect in order to make the research effective. Perhaps she keeps a notebook or reflective diary. Then, once the project is largely complete, she sits down to record her reflections in a scholarly article [18]. She is an experienced and diligent researcher, so she has kept bibliographic details and other relevant notes. She is able to frame her research in terms of research question, methodology and literature review. That earlier reflection on writing is now poured into the mould (the form or medium) of the scholarly critical-reflective article. It is represented, or perhaps reconstructed (from memory, from notes), in a more or less universal form which makes it available to other practice-researchers. 
In other words, reflection is a prior, chaotic, perhaps partly non-verbal activity which richly supports the production of creative work, but which is represented after the fact in a tidy scholarly form. And that scholarly form may be a misrepresentation, since as writer-researchers (indeed perhaps all researchers) know and privately acknowledge, we don't always formulate research in terms of research question, literature review, methodology, or if we do it may be partly for the benefit of funders and institutions, or we might formulate it in that way for ourselves in order to clarify the project, but then proceed in a less regimented way on the basis of hunches, guesswork and intuition.

The representation of reflection in written form after the fact may therefore misrepresent or falsify the practice element of the research by eliding some elements or features of reflection (intuition, non-verbal features, inchoateness) even as it imposes or emphasises others (the scholarly apparatus which is supposed to underpin the work's status as research). But rather than talking about misrepresentation, we would like to talk about distortion - the likelihood that 'writing up' reflection on practice into the classic scholarly article is likely to distort practice, like a strangely shaped mirror in a hall of mirrors, making some areas of the body bulge and others thin to almost nothing [19].

Of course, we must acknowledge that knowledge is also produced in the act of writing, and our reflection may not be complete before we begin writing it up in an article - it may in fact be completed by it. It might be that some insights about the writing process only occur to us in retrospect. And we might well feel that the act of writing an article enables us to clarify what we think, and that getting rid of some of that inchoateness, and translating the non-verbal into the verbal, is exactly what writers are in the business of doing.

We would not dispute any of that, and we are not interested in this article in attacking the validity of the scholarly article as a medium of reflective outputs. Much of our own recent research has emerged from the paradigm of critical reflection, framing a research question and a methodology, outlining the critical literature, and describing a research process using all the scholarly apparatus, all written up in a paper for submission to a journal. We remain committed to the scholarly article. What we suggest though is that it is not a neutral medium, but one which can distort reflection on creative practice precisely by the demands it makes in order to satisfy the requirements of academic rigour.

We suggest that reflection on practice might make use of a wider range of forms and media, none of them neutral, all of them distorting practice, but distorting it in illuminating and useful ways. Clearly the nature of the research might help to shape an appropriate form for the reflective element. Here, we want to consider some possible approaches to reflection, and why they might be worth pursuing. We do not make claims for innovation, and in several cases there are already existing examples, but we do want to suggest that there should be more examples, and that the discipline should be open to the claims of these non-standard approaches to produce and inscribe knowledge.

First, we might think about issues of tone and voice. We have argued that the orthodox scholarly voice is not neutral. There may be scope within the confines of the scholarly article to challenge and expand that voice. This may range from softening scholarly diction in order to create the impression of hearing a writer's 'real' voice, to changing the mode to be less argumentatively rigorous and more exploratory, to perhaps removing scholarly apparatus such as footnotes as a way of reflecting more faithfully the kind of on-the-hoof, non-underpinned thinking that writers often perform. Clearly this shades into the non-academic essay, which abandons certain claims about scholarly rigour but may assert certain other claims about practical usefulness. It is worth noting that, for good or ill, classic reflective texts by writers were often not produced in or for an academic context.

We might think of fictocriticism, creative work which performs its own reflection. We might look at the reflective opportunities provided by verse (look at Pope's 'Essay on Criticism' [1963]) or by graphic novels (Nick Sousanis' Unflattening was a PhD thesis in that form [2015]), or by dance, photography, painting, etc. Clearly using creative practice to reflect on creative practice might make some colleagues, and institutions, nervous. But we need to think as a discipline about whether we shape our texts in order to fit the REF and other institutional contexts, or whether we shape those contexts to fit the kind of outputs that would really advance thinking and practice in creative writing. The reality is that we ought to be doing both.

In suggesting that creative practices might provide a way of reflecting on creative practice, we hope to suggest the idea of conversation, between practices and between practitioners. The conversations we have with other writers are often highly productive of both insights about practice and new ideas for our writing, and the conversation - or interview - presents an 
opportunity to generate a different kind of reflection from the single-author scholarly article (e.g. Watkins \& Krauth 2016).

There is also the notion of documentary. Other creative practices in the academy which are not verbal in nature (such as fine art) typically document their processes alongside reflecting and contextualising in words. Creative writing research has less of a tradition of documenting process [20], and this represents an area with large potential for the future: a documentary mode of reflection which seeks not so much to analyse or contextualise (though those are important tasks) but to illustrate clearly how writing happens. Scholarly practices tend to promote authority and deprecate chance and guesswork, but honest presentation of our hesitations, false starts and anxieties might produce a knowledge about writing which is more useful for other practitioners.

This idea comes back to the question of how the medium of reflection distorts matters. There is no doubt that some of the more fanciful forms we have suggested would elide much of the apparatus that promotes scholarly rigour - detailed referencing, close analysis, setting in context, framing research in orthodox ways. This might often constitute a material loss to the research. But that apparatus itself can elide some of the features that a documentary or dialogic or creative approach might allow: the roles of guesswork and intuition, the nuances of the non-verbal (including body language), hesitation, the inviting qualities of tone and form which might make insights more or differently available to the reader.

In this thinking we are guided by the ideas of non-representational theory, as developed for example by Nigel Thrift in the field of geography, which says that knowledge as represented through (particular forms of) words will always be a subset of, or a distortion of, a lived practice (Thrift 2007). Of course, our practice involves working with words, but that does not mean that words themselves are always adequate to describe how we work.

Finally, and perhaps ultimately, we would like to acknowledge that some aspects of writing might be beyond all forms of reflection. In one of his Letters to a Young Poet, Rilke wrote that

Nothing touches a work of art so little as words of criticism: they always result in more or less fortunate misunderstandings. Things aren't all so tangible and sayable as people would usually have us believe; most experiences are unsayable, they happen in a space that no word has ever entered, and more unsayable than all other things are works of art, those mysterious existences, whose life endures beside our own small, transitory life. (Letter 1, 17 February 1903, in Rilke 1934)

We learn to write, in the end, by writing, and though it is a requirement in the academy that we produce knowledge that is accessible to others, we cannot make everything accessible. But we can try to make as much accessible as we can, as usefully as possible and with an eye for the disparate ways in which practice can be described and accessed.

\title{
Notes
}

[1] The Research Excellence Framework (REF) is the system for assessing the quality of research in UK universities and higher education colleges (see: https://www.ref.ac.uk/). The key purposes of the REF are:

\author{
to inform the selective allocation of funding for research; \\ to provide accountability for public investment in research and produce evidence of the \\ benefits of this investment; \\ to provide benchmarking information and establish reputational yardsticks, for use in the \\ higher education sector and for public information.
}

This major exercise is undertaken roughly every 6 years by the four UK higher education funding bodies (the Higher Education Funding Council for England, the Higher Education Funding Council for Wales, the Scottish Funding Council and the Department for the Economy in Northern Ireland). return to text

[2] 'The Future of Practice Research' symposium held at Goldsmiths, University of London, was hosted in partnership with the Higher Education Funding Council for England (HEFCE funds and regulates universities and colleges in England) on 4 June 2015. This event gave an opportunity for researchers, practitioners and research managers to explore new ways in which practice research is extending, and to influence broader agendas around assessment, funding and impact in a period of constant change. return to text

[3] We use the term 'practice research' to refer to research in which the activity of creating is the primary research method, with critical understanding being drawn from investigating that practice. In this we follow Hann, who argues that the term 'avoids the micro-politics of practice as/through/based/led' and 'focuses on the wider issues related to how researchers share, apply and critique knowledge borne of practice' (Hann 2015). return to text 


\section{Michael Cawood Green \& Tony Williams TEXT Vol 22 No 1}

[4] Our interest in the 'reflective' element required of practice research means that, perhaps oddly, creative writing (our primary concern in this paper) is included under the category 'non-textual'. This is the generic term used by the REF for practice research in which the evidence base requires additional or supplementary material establishing its status as research. See also footnote 12 below. return to text

[5] The Research Assessment Exercise (the primary purpose of which was to produce quality profiles for each submission of research activity made by institutions and took place in 1992, 1996 and 2001) was replaced by the Research Excellence Framework in 2014. return to text

[6] The UK Arts and Humanities Research Council tends to use the term 'practice-led' as a generic term for practice research; where appropriate we have followed this usage. return to text

[7] Submission of outputs 71:

In order to form an expert judgment on the quality of each research output, sub-panel members will examine such evidence as needed. Where the research content of the output may not be self-evident, submitting units should supply additional information as specified in b below. A 'portfolio', as specified in c below, should only be included where the research output and 'information about the research process and/or content', together, do not provide material sufficient to assess the output. Institutions should, therefore, submit only such evidence as they deem necessary to enable sub-panel members to properly assess a research output, within the following guidelines: a. Research output: This should be submitted without additional material where the output is in itself deemed to constitute sufficient evidence of the research. $b$. Information about the research process and/or content: Submitting units may include a statement of up to 300 words in cases where the research imperatives and research process of an output (such as an artefact, curation, database, digital format, installation, composition, performance or event, screening, tape, creative writing, database, textbook, translation or video) might further be made evident by descriptive and contextualising information. Where the location or medium of the output is essential to a proper understanding of the research being presented this should be explained in the 300 words. The sub-panels will ignore any additional material that includes evaluative commentary on the perceived quality of a research output. c. Portfolio: In cases where the research output is: ephemeral (for example, time-based, nonmaterial, or no longer available); is one in a series of interconnected works (for example, performances or installations); or cannot fully represent its research dimensions through the evidence provided in $\mathrm{a}$ and $\mathrm{b}$ above, a portfolio in either digital or physical form may be submitted. This material must be sufficiently substantial to constitute evidence which will allow sub-panel members to access the research dimensions of the work. The expectation is that a portfolio is likely to include complementary evidence about the processes and outcomes of the work, for example DVDs, tapes (video and audio), photographs, sketchbooks, web-sites, catalogues, interviews or programme notes. The material should be presented with the sole purpose of assisting panel members to access fully the research dimensions of the work. (REF2014 2012: 87) return to text

[8] This unease is commonly reported across the subject area of Creative Writing (see Graham Mort's paper as discussed below), although it must be recognised that under 'Disciplinary developments' in UOA 29: English Language and Literature', 'The sub-panel noted a significant increase in the variety and volume of creative writing and creative practice, submitted from institutions of differing size and character. The best of this work was outstanding in terms of its originality, rigour and significance, extending the traditional boundaries of research in the discipline of English in absorbing and sometimes exhilarating ways. A significant proportion of the creative writing submitted for assessment was judged to be of world-leading quality' (REF2014 2015: 45). return to text

[9] Creative Writing is specifically identified as one of the areas where more work may have to be done with regard to 'distinguishing between advanced practice presented as research, and practice-based work that fulfilled the definition of research as set out for REF2014': 'The international members ... commented that, in the case of text-based creative writing, where the history of assessing such material is more recent, there may be need for further review in the future' (REF2014 2015: 24). return to text

[10] Brown makes no specific reference to Sub-panel 29: English Language and Literature, in which Creative Writing was included, without being mentioned as an individual subject other than in one parentheses (see below). Creative Writing was the subject of 'Cross sub-panel working': 'SPs 28 and 29 cross-calibrated with respect to Linguistics and Creative Writing, and advice was provided by SP 29 on the assessment of Creative Writing outputs where requested by other sub-panels, with particularly close working between SPs 28 and 29 with respect to such outputs' (REF2014 2015: 10). return to text

[11] The REF awards an overall quality profile to each submission, using four starred levels: these range between a four, which is awarded to work rated as 'world-leading in terms of originality, significance and rigour,' and a one, which is awarded to work rated as 'recognised nationally in terms of originality, significance and rigour.' A submission is rated as 'Unclassified' if it 'falls below the standard of nationally recognised work. Or work which does not meet the published definition of research for the purposes of this assessment' (see https://www.ref.ac.uk/2014/panels/assessmentcriteriaandleveldefinitions/). return to text

[12] As noted above, we take this point to apply to all forms of practice research. In REF2014, creative writing was only included under practice research if a portfolio was provided. See note on 'Practice Research' in REF2014: 'In this instance this term should not be taken to include creative writing where research portfolios were not provided' (REF2014 2015: 16). return to text 
[13] A fuller account is given in the REF2014 report, which contains the following comments:

In brief, the additional 300 words to make further evident the research imperatives and/or research process of an output (paragraph 71(b) of the 'Panel criteria') were used inconsistently and the question of the research imperative was not always well-articulated. (2015: 16) As in 2008 the best outputs in PaR were distinguished by clearly articulated research objectives. In a number of instances, the presentation of practice needed no more than a wellturned 300-word statement to point up the research inquiry and its findings, since the concerns outlined were then amply apparent within the practice itself (which was made available for assessment by a variety of means including DVD or CD recordings, photographic materials, scripts and scores, databases, etc). (2015: 99)

More generally, the 300 word statements too often displayed a misunderstanding of what was being asked for and provided evidence of impact from the research, or a descriptive account akin to a programme note, rather than making the case for practice as research. (2015: 100) return to text

[14] See the AHRC's Definition of research:

Our primary concern is to ensure that the research we fund addresses clearly-articulated research questions, issues or problems, set in a clear context of other research in that area, and using appropriate research methods and/or approaches. ... Creative output can be produced, or practice undertaken, as an integral part of a research process as defined above. The Council would expect, however, this practice to be accompanied by some form of documentation of the research process, as well as some form of textual analysis or explanation to support its position and as a record of your critical reflection. Equally, creativity or practice may involve no such process at all, in which case it would be ineligible for funding from the Arts and Humanities Research Council. (Arts and Humanities Research Council 2015) return to text

[15] Panel criteria and working methods. Note that under Section D2: Assessment criteria: outputs, 'creative writing and compositions' are listed together as 'Output types' (REF2014 2012: 85). return to text

[16] As Reeves states:

if the REF is to continue down the road of requiring composers to articulate their research through written texts, and to assess it on that basis, the future progress of compositional research will be delimited and retarded by the ability to explicate it in writing. It will encourage the exploration of certain things over others: those for which we already have written terminology, rather than those for which we do not. In other words, composers will be forced to value the potential for written explication of their work over compositional innovation as such in determining the future direction of their research. This will hold back the discipline, rather than help to advance it. This is the opposite of what research is supposed to do. (Reeves 2015: 3) return to text

[17] If in some cases only for a specific audience: for someone like Reeves, compositional research should 'not require logo-centric explication for it to be apparent so long as those involved in its identification are highly and widely experienced composers themselves' (Reeves 2015: 1). return to text

[18] It is true of course that creative writers may carry out literary-critical research alongside practice, without a significant reflective component. In that case the relation between the practice and the critical work may be left implicit - an elision which might be helpful or unhelpful (and perhaps both, in different ways). But in this section, we assume that the writer is producing a scholarly article which articulates her practice more or less explicitly, and that in doing so she reflects on her own practice and/or the practice of others. That is to say, although critical readings of texts can support practice research, our focus in this article is on supplementary discourses which treat practice explicitly as practice. return to text

[19] We would acknowledge that this sketch of the scholarly article as 'writing up' the practice research risks reducing the nuanced relationship between a piece of practice research and an accompanying critical output which might, for example, explore the same research question by other means and would therefore not map so neatly on to the practice as an 'articulation' of it. Perhaps at the heart of the issue, though (and at the heart of our paper), is the way the scholarly article establishes a particular voice as the appropriate supplement to practice; 'when writers are talking about writing, this is how they (must) speak'. return to text

[20] This is the case despite, as we note above, process being a crucial part of the Arts and Humanities Research Council 'Definition of Research': 'Creative output can be produced, or practice undertaken, as an integral part of a research process,' but it 'expects ... this practice to be accompanied by some form of documentation of the research process, as well as some form of textual analysis or explanation to support its position and as a record of ... critical reflection' (2015). return to text

\section{Works cited}


Arts and Humanities Research Council 2015 'Definition of Research', Research Funding Guide: http://www.ahrc.ac.uk/funding/research/researchfundingguide/introduction/definitionofresearch/ (accessed 3 April 2015) return to text

Bourke, N \& P Neilsen 2004 'The Problem of the Exegesis in Creative Writing Higher Degrees,' TEXT Special Issue No 3: http://www.textjournal.com.au/speciss/issue3/bourke.htm (accessed 23 March 2016) return to text

Brady, T 2000 ‘A Question of Genre: de-mystifying the exegesis', TEXT: Journal of Writing and Writing Courses 4, 1: http://www.textjournal.com.au/april00/brady.htm (accessed 2 February 2016) return to text

Brien, DL \& M McAllister 2016 'Becoming authentic multidisciplinary or interdisciplinary researchers: methodological practices and outcomes', TEXT Special Issue 34: http://www.textjournal.com.au/speciss/issue34/Brien\&McAllister.pdf (accessed 19 November 2017) return to text

Brown, B 2015 'Different Perspectives: Talk 3 - The Future of Practice Research' symposium held at Goldsmiths, University of London, hosted in partnership with HEFCE. Podcast:

https://futurepracticeresearch.files.wordpress.com/2015/08/the-future-of-practice-research-bruce-brown-design-provice-chancellor-for-research-university-of-brighton.wav (accessed 21 August 2017) return to text

Coetzee, JM 2007 Diary of a Bad Year, Harvill Secker, London return to text

Croft, J 2015 'Composition is Not Research', Tempo 69, 272: 6-11 return to text

Dewey, J 1998 [1933] How we think: a restatement of the relation of reflective thinking to the educative process, Houghton Mifflin, Boston return to text

Dimock, WC 2017 ‘Editor’s Column - Experimental Humanities’, PMLA 132, 2: 241-249 return to text

Gupta, S 2010 [1998] 'Institutional histories of literary disciplines', in D Da Sousa Correa \& WR Owens (eds) The Handbook to Literary Research, Routledge, Abingdon: 89-108 return to text

Hann, R 2015 'Practice Matters: Arguments for a "Second Wave” of Practice Research', The Future of Practice Research (28 July): https://futurepracticeresearch.org/2015/07/28/practice-matters-arguments-for-a-second-wave-ofpractice-research/ (accessed 27 September 2017). See also: R Hann 2017 'Second Wave Practice Research': $\mathrm{http} / /$ prezi.com/i1u2ufdobaub/?utm_campaign=share\&utm_medium=copy (accessed 27 September 2017) return to text

Hetherington, P 2010 'Some (post-romantic) reflections on creative writing and the exegesis', TEXT Special Issue 8: Creative and practice-led research: current status, future plans: www.textjournal.com.au/speciss/issue8/Hetherington.pdf (accessed 23 October 2017) return to text

Krauth, N 2011 'Evolution of the exegesis: the radical trajectory of the creative writing doctorate in Australia', TEXT 15, 1: http://www.textjournal.com.au/april11/krauth.htm (accessed 17 May 2016) return to text

McNamara, A 2012 'Six rules for practice-led research', TEXT Special Issue 14: http://www.textjournal.com.au/speciss/issue14/McNamara.pdf (accessed 5 December 2015) return to text

Milech, BH \& A Schilo 2004 “"Exit Jesis”: relating the exegesis and the creative/production components of a research thesis', TEXT Special Issue 3: http://www.textjournal.com.au/speciss/issue3/milechschilo.htm (accessed 19 July 2017) return to text

Mort, G 2013 'Leverets' (short story) with linked reflective essay 'The Bokeh and Beyond', Short Fiction in Theory and Practice 3, 1: 5-23 return to text

Nelson, R 2013 Practice as Research in the Arts: Principles, Protocols, Pedagogies, Resistances, Palgrave, Basingstoke return to text

Pace, I 2015 'Those 300-word statements on Practice-as-Research for the RAE/REF - origins and stipulations 'academic butt-covering' or more problematic?', Desiring Progress [blog] (16 December): https://ianpace.wordpress.com/2015/12/16/those-300-word-statements-on-practice-as-research-for-the-raeref-originsand-stipulations-academic-butt-covering-or-more-problematic/ (accessed 19 October 2017) return to text

Pace, I 2016 'Composition and Performance can be, and often have been, Research', Tempo 70, 275: 60-70 return to text

Perry, G 1998 'Writing in the Dark: Exorcising the Exegesis', TEXT 2, 2:

http://www.textjournal.com.au/oct98/perry.htm (accessed 4 July 2017) return to text

Pope, A 1963 [1711] 'Essay on Criticism', The Poems of Alexander Pope: A One-Volume Edition of the Twickenham Text with Selected Annotations, Methuen, London: 144-68 return to text

Reeves, C 2015 'Composition as Research', Royal Music Association: https://www.rma.ac.uk/news/2015-practice-asresearch-CR.pdf (accessed 13 March 2017: the online link has since been removed. This is a pity, as this seminal paper has never been formally published and was only circulated in hard copy other than at this link.) return to text

REF2014 2012 'Panel criteria and working methods. Main Panel D criteria', Research Excellence Framework 2014: http://www.ref.ac.uk/2014/media/ref/content/pub/panelcriteriaandworkingmethods/01_12_2D.pdf (accessed 21 August 2017) return to text 


\section{Michael Cawood Green \& Tony Williams TEXT Vol 22 No 1}

REF2014 2015 'Overview report by Main Panel D and Sub-panels 27 to 36', Research Excellence Framework 2014:http://www.ref.ac.uk/2014/media/ref/content/expanel/member/Main\%20Panel\%20D\%20overview\%20report.pdf (accessed 21 August 2017) return to text

Rilke, RM 1993 [1934] Letters to a Young Poet, WW Norton, New York return to text

Schön, D 1983 The Reflective Practitioner: How professionals think in action, Temple Smith, London return to text Sousanis, N 2015 Unflattening, Harvard University Press, Cambridge MA return to text

Thrift, N 2007 Non-representational theory: Space, Politics, Affect, Routledge, London return to text

Watkins, R \& N Krauth 2016 'Radicalising the scholarly paper: New forms for the traditional journal article', TEXT 20,1: http://www.textjournal.com.au/april16/watkins\&krauth.htm (accessed 13 May 2016) return to text

Williams, P 2016 'The Performative Exegesis', TEXT 20, 1: http://textjournal.com.au/aprill6/williams.htm (accessed 19 July 2017) return to text

Michael Green is Professor in English and Creative Writing at Northumbria University and Fellow of the University of KwaZulu-Natal. He is the author of Novel Histories: Past, Present, and Future in South African Fiction and numerous journal articles and book chapters. As Michael Cawood Green he has published two works of historical fiction, Sinking: A Verse Novella and For the Sake of Silence for which he was awarded the Olive Schreiner Prize for Prose. His new novel, The Ghosting of Anne Armstrong, is due out in Spring 2019.

Tony Williams is Associate Professor in Creative Writing at Northumbria University. His novel Nutcase adapts The Saga of Grettir the Strong into a contemporary setting. All the Bananas I've Never Eaten won best short story collection in the Saboteur Awards, while his poetry has been shortlisted for the Aldeburgh, Portico and Michael Murphy prizes, and has been a PBS Pamphlet Choice. He also works in collaboration with the film-maker Alan Fentiman.

\section{TEXT}

Vol 22 No 1 April 2018

http://www.textjournal.com.au

General Editor: Nigel Krauth. Editors: Julienne van Loon \& Ross Watkins

text@textjournal.com.au 